\title{
Eco-translation of Local Knowledge in Developing a Trilingual Glossary of Fishing and Aquaculture
}

\author{
Rosarito T. Suatengco ${ }^{1 \star}$, Hazel D. Joaquin ${ }^{2}$ \\ ${ }^{1}$ Far Eastern University, Manila Philippines \\ ${ }^{2}$ Capiz State University, Capiz, Philippines
}

\begin{abstract}
A B S T R A C T
The eco-translation approach offers a new perspective to translate concepts in fishing and aquaculture. It focuses on ecological meanings of local knowledge (LK). Such knowledge, embedded in the local language, Hiligaynon, is used as an impetus for developing a trilingual glossary of fishing and aquaculture. Eco-translation becomes the theoretical springboard for translating Hiligaynon words in Filipino and English. The gathering of word tokens is informed by linguistic ethnography, a research method that focuses on the description of the community experiences, activities, and appreciation of its ecology. The LK is presented through the fisherfolk's narratives of their cultural experiences, identification, and analysis of local fishing and aquaculture word tokens, along with its validation. The trilingual glossary highlights the concepts on preparations, harvesting, and marketing of fishing and aquaculture. Evidently, the community uses its LK through its language to create concepts for fishing and aquaculture that represent its own culture and ecological experiences.
\end{abstract}

E-mail address: rsuatengco@feu.edu.ph*

Received: February 15, 2019

Accepted: May 8, 2019
Keywords: Eco-translation, local knowledge, fishing and aquaculture, trilingual glossary

\section{I N T R O D U C T I O N}

$\mathrm{F}_{\mathrm{n}}^{\mathrm{i}}$ shing and aquaculture farming is an everyday economic activity of coastal communities in the Philippines. The government has invested a large number of resources in research to develop technologies which will modernize fishing and aquaculture methods; these increase the economic potentials of fishing and aquaculture farming in the country. However, the existing instructional materials about these technologies are written in a language which does not represent the community's local knowledge of fishing and aquaculture farming. The need to make these instructional resources more accessible to farmers can only happen if these are written in their local language, Hiligaynon. Fisherfolk in the Philippines more often depend on their LK in creating a shared understanding of fishing and aquaculture farming generation after generation. Their LK becomes the main source of information for this economic activity; it is centrally embedded in their language, Hiligaynon.

The local knowledge has practically provided coastal societies with 'empirically-based and practi- cally oriented' (Ruddle 2000) avenues for creating their systems of understanding their own ecology. The socio-cultural importance of LK highlights the transmission of knowledge, practices, habits, social roles, and the construction of new knowledge from one generation to the next. LK provides information on rural activities and practices, land management, oral traditions and symbolism, rituals and ceremonies, and other community features, endeavors, and patterns (Carvalho and Frazao-Moreira 2011), as well as the human-environment interaction (Raymond et al. 2010). Carvalho and Frazao-Moreira (2011) argue that local knowledge can be an impetus for new insights and opportunities on promoting sustainability and preservation of cultural and ecological diversity.

In identifying the LK for the coastal marine environment, the context is presented based on the community's understanding of their eco-system (Ruddle 2000), the fish behavior (Palomares and Pauly 1992; Ruddle 1993; Ruddle and Akimichi 1989), the physical environment, and the fish habitats and movements (Nietschmann 1989).

The concept of local knowledge is well appli- 
cable to marine resources; the literature on LK emphasizes the utilization of domestic resources and the management of natural habitats and agro-systems; moreover, it shows the importance of LK to fishers in making decisions-knowing when, how and what to fish, and understanding the fishing concepts (Ruddle 2000).

Fishing and aquaculture practices of the coastal community become the centerpiece of the study which is anchored on the local language, Hiligaynon; the language becomes an avenue to show the relationship of the fishing and aquaculture practices with the ecology of the community. Such is seen through the fishing practices which include the naming of fish based on their special behavior and physical features (Ruddle 1993), and providing the language for the impact of the ecology on harvesting and marketing. This study shows the weaving of local knowledge and language with the community's ecology, the bedrock for understanding their fishing and aquaculture practices.

Hiligaynon, also known as Ilonggo, is one of the regional languages in the Philippines, spoken by more than 6 million Filipinos in the Panay group of islands in the country. It belongs to the Bisaya group of the Austronesian family of languages (Ethnologue 2018). The challenge for this study is to bring out the LK of fishing and aquaculture from its source language, Hiligaynon, to other languages widely spoken in the country, Filipino and English, without compromising the inherent meanings and subtleties of the source language. Thus, eco-translation becomes the apt anchor of the translation processes.

Eco-translatology was developed as the "translation theory of adaptation and selection." (Hu 2011). Eco-translation is now used as a theory to translate literature works, advertisement, public signs, and film titles, among others ( $\mathrm{Hu}$ 2008; Du 2012). Compared with other translation theories, eco-translation theory focuses on macro and systematic research, which has developed a new vision for translation studies.

It can be said that eco-translation theory and criticism in literary translation is on the rise, which poses a challenge to traditional literary and cultural translation studies' doctrine. However, in contemporary translation studies, a considerable number of scholars are skeptical of the significance and vitality of this branch (Zhang 2017). Current translation trends show the growth of eco-translation to inform socio-cultural phenomenon (Babelyuk and Galaidin 2018). In the study of Polish and Ukrainian contem- porary translation studies, it is proven that eco-translation provides the translation process a more substantial approach in understanding the local knowledge from the source language to the target language (Babelyuk and Galaidin 2018).

Babelyuk and Galaidin (2018) claim that eco-translation can be viewed from an ecological and cultural perspective. Eco-translation emphasizes transnational eco-movements, eco-texts, and ideas which can be used to understand eco-translatology, a perspective that adheres to the processes of adaptation and selection across cultures. In this type of translation, the translator actively maintains the integrity of translational ecosystems. With eco-translation, the main contribution is to promote and develop culture, languages, and cultural identities (Babelyuk and Galaidin 2018).

The translation is undertaken, to make eco-translation an effective mean for cultural promotion, through a meticulous procedure, method, and process that will create a clear synergy between the source language and the target language or languages, as shown in a trilingual glossary. The eco-translation tasks include making a copious collection of word tokens and translating these tokens based on its ecological and cultural vision (Hu 2011b). Eco-translation shares Newmark's (1988) perspective of translation based on the cultural dimension of the source language. Newmark (1988) believes that the untranslatable word tokens are analyzed based on the context in which the speakers use them.

In translations, one common problem is the different renditions of the translation of words and meanings; this problem is possible due to cultural differences of translators who are products of their own beliefs, attitudes, customs, and traditions. This difference in culture brings possible problems or difficulties in doing translations. If different renditions of translation happen in the conduct of the study, the rule of the majority is to be executed. Velardi et al. (2014) noted that knowledge could have different meanings, and a glossary is a byproduct of an appropriate mechanism to avoid misunderstanding in knowledge transmission. The goal is to make the knowledge accessible by unifying the language used in representing explicit knowledge (Velardi et al. 2014).

Eco-translation is understood through adaptation and selection of the translator, translation principle and method, multidimensional selective adaptation and adaptive selection, three-dimensional transformations-linguistic, cultural, and communicative dimensions, evaluation criterion, multi-dimen- 
sional transformations, the readers' feedback, and the translators' quality ( $\mathrm{Hu}$ 2004). Hu's eco-translation theory provides a more adept equivalency of Hiligaynon fishing and aquaculture concepts. It looks into 'ecology' as the centerpiece in making arguments for translation, and attempts to interpret and examine translation from the perspective of eco-reasoning characterized by wholeness and relevance, seeking dynamics and balance, reflecting eco-aesthetics, identifying the translation community, adhering to translation ethics, and highlighting unity and diversity (Hu 2011a).

The perspective in the eco-translation of the local knowledge for fishing and aquaculture is the interweaving of ecological and cultural truths embedded in the Hiligaynon language; hence, it has adopted tedious procedures that result in a seamless weave between Hiligaynon, as the source language, and English and Filipino, as the target languages. The apparent connection between the community's ecology and its language is shown in the translation processes through the eco-translation approach. Since this study will be a multilingual eco-translation from Hiligaynon to Filipino and English, the translation process also partly draws support from Newmark's (1988) perspective on translation. The translation's primary goal, then, is to maximize the limits of the context by 'revealing the ecological mechanism of translatability' which can provide perspectives in translating the indigenous concepts. In eco-translation, a translation introduces new interpretations of the translatability or untranslatability of fishing and aquaculture concepts.

Considering all these, translation and LK together with the development of a trilingual glossary can be useful in accessing accurate information that can be readily available to the community's fisherfolk. Translation, therefore, becomes a process or a result of converting information from a language or language variety into the target language. Given the need for accessible information for fisherfolk, a trilingual glossary anchored on LK becomes an essential product of eco-translation.

\section{MATERIALS AND METHODS}

\subsection{Research Design}

The linguistic ethnography was utilized to develop a multilingual glossary of fishing and aquaculture terms; the processes were anchored on eco-translation of the source language, Hiligaynon, to the national language, Filipino, and an official lan- guage, English. Linguistic ethnography looks into the convergence of language and social life as they mutually shape together; it reveals and provides insights on the dynamics of social and cultural activities and experiences of the people on a daily basis (Maybin et al. 2007). On translation, the eco-translation focuses on the 'ecological' meaning of the concepts in which the translation takes into perspective the examination of fishing and aquaculture concepts from eco-holism. Hence, eco-reason is used to argue for the translation of concepts which stress wholeness and relevance, seek dynamics and balance, adhere to the translation community, reflect eco-aesthetics, and highlight diversity (Hu 2011a). As such, in the analysis of the gathered fishing and aquaculture tokens, the eco-translatology perspective is utilized.

\subsection{Data Gathering Techniques}

Immersion was the centerpiece of data gathering processes of this study because it allows data gatherers to be involved with the community and its activities; furthermore, it allows them to respond and reflect on events as they happen since they experience these activities themselves (Goffman 1989).

Through immersion, fishing, and aquaculture tokens from the source language were identified. These tokens came from the two families involved in this study; fishing and aquaculture farming have been the families' source of livelihood for more than three decades. The immersion was undertaken for two weeks. A letter requesting consent to undergo immersion was handed to the barangay captains of the two barangays where the immersion activities took place. Permission from each family member was also sought in this study.

The first week of immersion was spent with a family who owns and manages a fishpond in Sapian, Capiz; it is a popular fishing community in the Panay islands in the Philippines. The immersion was timed during the harvest season to observe and participate in the harvesting of fishpond, marketing harvest, and preparing the fishpond for the next culture.

The second week of immersion was in Pontevedra, Capiz located at the First District of Capiz. Immersion was done with a family whose main source of living is also fishing, which they have been doing for more than 35 years. Immersion was evident through the observation and participation in some traditional fishing activities and routines done by local fishermen in the community.

Field notes, through daily notes, were writ- 
ten after the observation and participation in fishing activities. Conversations of and with fisherfolk were likewise written down. There were instances that the fisherfolk would explain the local context of the conversation. Written records of the impressions were jotted down, which highlight key words and phrases capturing the ecological and indigenous meanings of the words; this process resulted in an accumulated written record of fishing concepts based on LK. A checklist of fishing and aquaculture terms used by fisherfolk was compiled. The value of field notes in data gathering is that the experiences are described and impressions that made research gathering more personal and involved (Emerson et al. 1995). The field notes allowed for the authentic identification of word tokens anchored on the natural occurrence of fishing and aquaculture concepts in the fisherfolk's spontaneous utterances. In sum, a triangulated qualitative data gathering techniques were applied to collect the fishing and aquaculture token in Hiligaynon, which provided a strong basis to assume that the tokens represent the LK of fisherfolk in Capiz.

\subsection{Participants}

There are four (4) groups of participants: fisherfolk, translators, experts, and expert-validators. The fisherfolk speak Hiligaynon in daily conversations and during economic activities, fishing and aquaculture farming.

In selecting the participants, the sources of word tokens, the fishing and aquaculture context in Sapian, Capiz was considered; that is, the study involved family members and their caregivers who worked together to produce, harvest, and market fish and aquaculture products. The participants have long been involved in fishing and aquaculture for decades. The locus of this study is a coastal municipality in Capiz, wherein the primary source of livelihood is fishing and aquaculture farming.

There are two (2) families selected for this study. Most of the members have been taking active roles in fishing and aquaculture activities; the first has three (3) members - father, mother, and caregiver who take active roles in aqua-farming at the family's fishpond for more than 40 years. The father has been in the aquaculture industry since childhood since his parents owned a fishpond. He eventually inherited the fishpond from his parents; he can be considered as second generation fisherman. He manages a fishpond, which is the family's main source of livelihood. His wife, meanwhile, came from a family of fishermen.
The caretaker is the couple's assistant who helps in all fishing and aquaculture farming activities. The fishpond is located beside the family's house and is surrounded by many households whose means of living is also fishing and aquaculture farming.

With the second family, the three generations of immediate and extended families have been involved in fishing and aquaculture activities for more than 50 years. Among the family members, it is the father, the mother, and their two sons with their wives who have been directly involved in fishing and cultivating the family's fishpond, their primary source of livelihood. The father has been into fishing for more than 70 years. Their family owns two boats which are used in fishing and transportation since a river surrounds their house.

The two families also acted as the LK and language informants; they gave explanations on how Hiligaynon word token for fishery and aquaculture are used in ecological contexts such as community experiences, LK concepts, and association of concepts with other concepts relevant to fishing and aquaculture farming.

The second group of participants is the five (5) translators of Hiligaynon fishing and aquaculture word tokens into Filipino, as a national language, and English, as an official language. These translators were selected because of the following: 1 ) they are native speakers of Hiligaynon who have comprehensive knowledge and facility on fishing and aquaculture; 2) they are fluent in the three languages-Hiligaynon, Filipino, and English; 3) they are familiar with the customs and culture of the source and target languages; and 4) they have skills in translating and writing a dictionary.

The third group is the five (5) language-experts who validated the translated words from Hiligaynon to Filipino and English. These were selected based on the following qualifications: 1) they are native speakers of Hiligaynon; 2) they are fluent and can write both in Filipino and English languages; 3) they have worked or engaged in fishing and aquaculture for at least five years; and 4) they have a strong background or comprehensive knowledge in fishing and aquaculture. The inclusion of language experts in this study responds to Larson's (1984) notion of the ideal translation, which should be accurate, clear, and natural.

To further guarantee the accuracy of word entries, the glossary was validated by some SUC (State Universities and Colleges) teachers in the Panay Island teaching fishery subjects and government agen- 
cies concerned with aquatic resources like the Bureau of Fisheries and Aquatic Resources (BFAR) and the Southeast Asian Fisheries Development Center (SEAFDEC) if the terms included were accurate and comprehensible.

\subsection{Research Procedure}

The procedures undertaken in making a trilingual glossary are the following:

1. Hiligaynon word token collection through an informal interview, field notes, and audio recording of conversations;

2. Selection of glossary entries after making a checklist of Hiligaynon terms collected, arranging the terms alphabetically, categorizing the terms as to what parts of speech they belong and provide a pronunciation key, classifying the terms into fishing and aquaculture, giving the meanings and definitions of terms using the field notes and with the help of fishery teachers, and using the entries terms in sentences;

3. Translation of Hiligaynon glossary entries which includes giving of definitions and sentence usage into Filipino and English languages, and finding an equivalent concept based on the principles of eco-translation;

4. The eco-analysis which includes analyzing culture-bound Hiligaynon fishing and aquaculture terms using Hu's eco-translation methods;

5. The trilingual-glossary making which involves the selection of glossary entries, describing the linguistic features of each entry, giving an ecologically apt context for the meaning, and using the entries in ecologically-enable sentences; and

6. The evaluation of the trilingual glossary, which includes providing experts' commentaries on the linguistic and non-linguistic descriptions of the tokens and revising the entries' descriptions based on these comments. Verification and validation were also done by asking some selected fishery teachers from SUCs in Capiz if the collected terms and their translations are accurate and existing or taught in the classroom and concerned agencies. Representatives from State Universities and Colleges from the Panay group of islands and prov- inces who teach fisheries and aquaculture courses, from the Bureau of Fisheries and Aquatic Resources (BFAR), and from the Southeast Asian Fisheries Development Center (SEAFDEC) all took an active role in validating the eco-translated multilingual glossary of fishing and aquaculture words.

In making the eco-translation for the trilingual glossary, the following were undertaken: the word-tokens were alphabetically arranged; the linguistic features like pronunciations, word forms, and meaning were provided for easy access to the target languages, Filipino and English; and the classification of tokens as fishing or aquaculture concept was given. Because of the application of the eco-translation process, the selection of Hiligaynon tokens has included phrases and compound words which authentically capture their ecological contexts.

An interesting feature in the eco-translation process is the construction of sentences for each glossary entry; the purpose is to initiate a means for better comprehension of the word token in all three languages-Hiligaynon, Filipino, and English, and to contextualize the identification of equivalents of the source language to the translated languages.

This is also meant to promote content validity in glossary making; content-related evidence of validity refers to the content and format of the instrument. It is a matter of determining if the content that the instrument contains is an adequate sample of the domain of content it is supposed to represent.

The expert-validators worked based on criteria used as a basis to judge the eco-translated multi-lingual glossary. The criteria are focused on the structure and content of an eco-translated multi-lingual glossary, representations of fishing and aquaculture corpus, linguistic features, ecologically used sentence constructions, the intelligibility of the concepts in Hiligaynon, Filipino, and English, and consistency of translation from the source language to the target languages. The eco-translation yielded results that highlight the authenticity and uniqueness of fishing and aquaculture farming in Capiz.

\section{RESULTS AND DISCUSSION}

3.1. Hiligaynon word tokens provide information on its linguistic uniqueness.

The LK of fishing and aquaculture presents an ecologically integrated understanding of Hiligaynon as it is used to present the community's culture. This is 
seemingly evident in its linguistic diversity of fishing and aquaculture word tokens which distinctly show its departure from the general linguistic knowledge of Hiligaynon. Hence, in the process of eco-translation, the need for the imminent appreciation of the fishing and aquaculture concepts, as used by the fisherfolk in the community, become a primary eco-translation challenge given the implications for adaption of LK to the Hiligaynon word tokens, as a source language to the target languages, Filipino and English. Likewise, the linguistic features of Hiligaynon word tokens for fishing and aquaculture show some features of distinctiveness from English and Filipino languages in terms of the presence of consonants, the consonant clusters, the emphasis of meaning, and the use of affixes.

The linguistic features of fishing and aquaculture words in Hiligaynon, as the source language in the translation process, have a combination of two-letter clusters with the prominence of the ' $y$ ' in the clusters, as well as the ' $k w$ ' sound clusters. There are five consonant clusters present in Hiligaynon fishing and aquaculture terms such as 'sy' for dibisyon, 'dy' for dyeneretor and dyako, 'pr' for kumpra and kumprador, ' $k w$ ' for kwadro and kwadrado, and 'tr' for traplin.

Another feature of the fishing and aquaculture word tokens is its sensitivity to stress as a meaning forming feature. For example, a stress mark for the word gapos can alter its meaning, which is indicated by an apostrophe ('). For instance, the word gapós when given stress on the second syllable is a noun which means tying materials, while the word gápos with stress on the first syllable is used as a verb which means to tie something. This shows that articulating the syllable of a word louder than the others would mean a change in meaning. In addition, the word garáb with stress on the second syllable used as a noun meaning sickle and the word gárab with stress on the first syllable was used as a verb meaning to harvest using a sickle. Again, the loudness of pronouncing the syllables of a word signaled a different meaning.

Evidently, in this translation process, the culture embedded in the source language is investigated based on how it represents the LK of the fishing folks (Bassnett 2012); hence, the culture, not the word token, becomes the operational unit of translation. The cultural factors become the centerpiece in the translation process (Bassnett 2012; Hu 2011b; Zhang 2017).

Another is of Hiligaynon affixes are bound morphemes that do not belong to a lexical category. The best exemplar of this is found in the word kumprador, which consists of the verb root kumpra which means 'buying products in bulk' and the affix -dor, a bound morpheme that combines with the root and gives the noun kumprador with the meaning 'buyer of the products in bulk.'

Evidently, the eco-translation process yielded an ecologically appropriate understanding of the linguistic features of the source language which then was used as the basis for finding their equivalence or determining if there is no equivalence in both Filipino and English.

3.2 The ecological inputs lead to a creative naming of fishing and aquaculture activities, products, and objects.

The word tokens for fishing and aquaculture present a characteristic of fisherfolk which can be summed into being creative. The fisherfolk gave names to activities, products, and objects which are practices and evident in the community. They used Hiligaynon as the main anchor to make these words accessible to the community. Again, it is apparent that the strong connection of fisherfolk to their ecology and language has enabled them to create words for their economic understanding and appreciation.

In the ecological context of the fisherfolk, naming a fish is a representation of the experience of how they used the water and sunlight to create fish products. For example, hubag- hubag or 'half dried fish' is used to emphasize that the fish is not well dried. In drying a fish, the fisherfolk depend on sunlight. If fish did not get enough sun exposure, it is called half dried; hence, the term hubag-hubag. Repeating the root word means an emphasis on the underexposure to the sun.

Flies are common insects that constantly swirl around fish products. Because of the fisherfolk's familiarity with these insects, a feature of a crab is named after it. Fisherfolk uses the word langaw-langaw, which means 'embryo of a king crab.' They compared to a langaw or fly the size of the embryo; hence, it is called langaw-langaw.

Hubag-hubag and langaw-langaw are both reduplicated words. Reduplication is a common linguistic phenomenon consisting of the repetition of the whole or part of a word which is found to a certain extent in probably all languages. It is used in inflections to convey a grammatical function, such as plurality, intensification, and others. Hiligaynon, like other languages, also follows reduplication pattern like in the fishing and aquaculture terms, hud-hud, hubag-hubag, into-into, lab-lab, kúsay-kúsay, lanap-lanap, pla-pla, langaw-langaw, and sudsud. It is usually formed by 
duplicating or repeating the first word or entire word. Reduplication in Hiligaynon tends to be limited to roots instead of affixes.

Hiligaynon fishing and aquaculture word tokens also have compounds like the word tinagongdagat meaning 'a fish sanctuary in Capiz', which was formed through combining the verb tinago meaning 'keep' and the noun dagat meaning 'a body of water.'

Some word tokens provide an idea of the behavior of fishes. For example, fisherfolk define some of their pasulang meaning to allow the fish to swim against the water current during transfer and harvest (pagpalangoy sa isda pasugata sa unos sang tubi sa tion sang pagsaylo o pagpahubas). The token pasulang originated from the word sulang which means to go against. The fishpond harvesters allow the fish to swim against the water current during harvest to be easily caught. They define it based on their actual observation.

3.3. The commonality of experiences among local fishing and aquaculture farmers with other communities lead to word borrowing.

In the process of eco-multilingual translation, the recognition of the availability of words in the target languages, Filipino and English, led to the adoption of equivalents which capture the authentic fishing and aquaculture activities of the community. For example, English loan words, such as trawl and phytoplankton, and Spanish loan words like bañera and kabayo de lamar are used by fisherfolk in Capiz. These loan words are spelled retaining their original spelling. In the same vein, sound translations between English and the official languages in each country are important research topics as well as a much-needed skill for translators (Munday 2012).

Hiligaynon fishing and aquaculture terms have synonymous words such as sagyap and sigin. The two words have the same meaning, which is 'made of abaca net or nylon screen operated by two persons along the beach or river banks to catch milkfish and prawns.' Antonym deals with words having opposite or dissimilar meaning like the entry words in the glossary, awas with the meaning 'the overflowing of water' and hubas meaning 'no water.'

The LK on fishing and aquaculture, as used in a natural ecology of the community, informed the selection of word tokens from the source language, Hiligaynon. The fisherfolk's discourse about their fishing and aquaculture activities provided cues on the presence of LK in fishing and aquaculture farming, which then was used in the eco-translation processes leading to the development of a trilingual glossary. In the conversation of fisherfolk, the word token bare$t a$, which means a 'block of mud', is used during the preparation of the fishpond for the next culture.

Bantay (Caretaker): Itambak ta na ang mga bareta sa pilapil. Mamala naina ah. Pwede na ibutang sa pilapil. [Let us now put the block of mud in the dike. It is now dry. It can be put now in the dike].

Mangingisda 1 (Fisherfolk 1): (Ginkamlot ang bareta nga lapuk). Huo, mamala na pwede na ini itambak sa pilapil. Sa diin unahon ta banda? Dasigon ta kay daw anyo maulan [Yes, it's dried already and can now be put in the dike. Where are we going to start first? Let us make it fast for it seems to rain].

Bantay (Caretaker): Hangayi ninyo nga indi mawasak ang binareta nga lapuk para indi na kita liwat magtagad. Didto kami umpisa malapit sa may gígí dampi sa likod. Kayuha ninyo ang pagplasta para indi magtalas ang pilapil kon may buhi na nga semilya [Take care that the mud of blocks will not be destroyed so that we will not dig again. You start first near the canal at the back. Put it properly to avoid leakage in the dike when fingerlings are released].

Mangingisda 2 (Fisherfolk 2): Okay ah. Maayo ang pagtagad ta sini kina aga. Sigurado ako indi na ini madul-ay [Okay. We dug it properly this morning. I'm sure it will not erode].

The conversation of aquaculture fishpond operators and owners showed that they define bareta as 'tinagad nga lapuk nga ginakamada para himo-on pilapil' [blocks of mud configured to make a dike]. This LK pertains to how fishpond operators and owners give meaning to the word bareta. The community's fisherfolk shares this understanding of bareta as local knowledge since it is is a common activity for fishpond operators to make a dike to hold water and prevent fish from swimming out of the fishpond. This activity became a practice which had been embedded in operating a fishpond.

The appreciation of the word token bareta exemplifies Gee's (1999) claim that meaning in a language is situated depending on the community where the language is used. The local knowledge of bareta is an illustration of fisherfolk's experiences and perceptions relative to fishing and aquaculture. 
3.4. The ecological use of word tokens stems from the historical local knowledge of fishing and aquaculture farming.

There are some fishing and aquaculture Hiligaynon words that have historical roots or viewpoints which had become part of the propagation of the cultural contexts of some fishing methods and fishing gears of the Panay-anon fisherfolk. This is best seen when performing activities prior to cultivating fishponds and doing fishing.

Bantay (Caretaker): Madabong na ang tubo sang lablab, Doy. Sa sunod semana basi pwede na ina kabuhi [Algae are now growing abundantly, Doy. Maybe we can release by next week].

Manong: Lantawon ko anay sa almanaki kon hunas o taob sunod semana. Kon sabagay lantawa lanap-lanap na ang tubi sa punong [I'll check it on in the almanac if it's low tide or high tide. Actually, the water in the fishpond is 'lanap-lanap' (water barely covering the pond's floor)].

Manong: Ang kadalumon bala sang tubi nagasapin-sapin sa salog sang punong. Kapareho sini hu ang tubi (Gintudlo ang tubi sa is aka dibisyon sang punong) [The deepness of water covers the fishpond's floor. The water is like this (Pointing to one compartment of the fishpond)].

Manong: Indi man gid tupong ah basta inang daw ga sapin-sapin lang bala [Not really level, but water covers the fishpond's floor].

Bantay (Caretaker): Nagapatima-an ina nga pwede na kapasulod tubi nga bag-o kagmagbuhi sang semilya. Kaluy-an lang maayo ang tyempo. Okay na ang semilya ta, Doy? [It is a sign that we can have the new water and then release of fingerlings. Hoping for good weather. Are the fingerlings ready, Doy?].

Another example is when fisherfolk do harvesting activities. Bare hands fishing is the beginning of man's fishing activities from which all other fishing techniques and gears have developed. The conversation below shows the local techniques of fisherfolk in catching crabs which have been embedded in their culture and language. There is a seeming dominance of naming word tokens showing the LK on fishing and aquaculture is best exemplified by persons, places, events, ideas, or things.
The presence of LK in fishing and aquaculture is best exemplified through nouns which provide information on the persons, places, events, ideas, and things that show the richness of fishing and aquaculture concepts in the community through their local language, Hiligaynon.

The word tokens represent the local knowledge on the names of fish, seashells, fishing methods, fishing gears, and fishing practices. Some examples are baslay, basnig, bastidor, bátog, batud, báwog, bayuyot, bigiw, and bihod.

The same observation was noted in their definition of the word pamuho meaning ginabuhuan kag ginaku-ot ang buho sa pagpanguha sang alimango' [to catch crab by burrowing in the mud]. The term pamuho originated from the word buho meaning a hole. As the name pamuh' suggests, the fisherman usually burrows or makes a hole in the mud and catch the crab inside it.

3.5. The naming words are further strengthened by the presence of loan words.

In this eco-trilingual glossary, there were some English loan words such as trawl, baby trawl, phytoplankton, and agar-agar and Spanish loan words like bañera, kabayo de lamar, merkado, obreros, pamuerta, pamuerta nga mayor, and segunta pamuerta which were used by fisher folks in fishing and aquaculture. These loan words were spelled in its original spelling except for dyako and dyenereytor. The use of English and Spanish loan words in carrying out everyday activities of fisherfolk is a reflection of American and Spanish influences that seemed to have been rooted in Capiz.

Loan words are words adopted by speakers of one language from a source language or different language. A loan word is also termed as borrowing. Borrowing is considered a result of cultural contact between two language communities like in the case of the Philippines, which had been colonized for years by Spain and America.

3.6. Local knowledge becomes more apparent when word entries are placed in a context of discourse.

When words are used in different discourse or sub-culture, it connotes different meaning as in the word bobo as in the following conversation:

Fisherfolk: Ah, ina ang kagingking? Bobo ang tawag sina. Daku ina nga lambat tapos gintambakan sang 
mga kagingking para makasiud isda kis-a kasag man o lukos ang nasisi-ud sina...[Oh, that bamboo twigs? That is called a fish pot. That is a big fishing net covered by tip portion of bamboo twigs to trap big fish, squid or blue crab].

In the conversation above, the word bobo or fish pot for fisherman means daku nga lambat nga natambakan sang kagingking para e si-ud sa dalagku nga isda, lukos o kasag [a big net covered by bamboo twigs to trap big fish, squid or blue crab]. However, when used in a different discourse or sub-culture like in Tagalog speaking places, the word bobo would mean 'not clever.' It was evident that the meaning of the word was different in two communities. This claim is supported by Gee's theory (1999) which holds that meaning in language is situated depending on the community where the language is used; this meaning is equivalent to the representation of the community's local knowledge.

Another LK is evident in the word token lapna. Fishpond operators and owners define lapna as ginapatubuan sang lab-lab nga ginakaon sang bangros'[place where blue-green algae are grown]. They associated the word lapna to a place where algae grew; this is a regular encounter in the fishing of fisherfolk. However, lapna means differently when used outside the fishing and aquaculture context. Outside the context of fishing, it means naglapta or 'widespread.'

In this sense, the meaning of the word is dependent on how it is situated in discourse. Evidently, the LK impacts the differences in how a community gives meaning to a word. Again, this is exemplified in the sample below:

Bantay (Caretaker) 1: Gapamuho para makadakop alimango (Ginaku-ot sang kamot ang buho sa duta). ['Gapamuho' to catch crab. Burrowing his hand in the mud's hole].

Bantay (Caretaker) 1: Naghalin ini sa tinaga nga buho gani gintawag nga pamuho kay sa buho nadakop ang alimango [It comes from the word hole (buho) that's why it is called 'pamuho' because the crab is caught inside the hole].

Bantay (Caretaker) 1: Huo amo ina. Dali lang kay daw may sulod ini ang buho [Yes, that's it. Just wait. It seems that there's a crab inside this hole].

Bantay (Caretaker) 2: Matambok ang alimango nga pinamuhuan sa punong. Inang natawag nila nga aligi- han bala. Samtang nagaku-ot man sa isa pa ka buho [Crabs caught by burrowing are fat. They called it with gonads, while burrowing his hand in the mud].

The word token pamuho originated from the word buho, meaning 'a hole.' As the name pamuho suggests, it has been embedded in the fishing culture that fisherfolk usually burrows or makes a hole in the mud and catch the crab inside it. That is why they called it pamuho for that is their description of catching crab inside the mud hole. The term has no specific equivalent or translation in Filipino and English for this manner of catching crab is specific on the culture of fisherfolk in the Province of Capiz. That is why it is considered a culture-bound word which belongs to one of Newmark's (1988) categorization of cultural words, which is a social culture that includes work and leisure. The term pamuho is one of the fisherfolk's terms for capturing crabs because before any fishing gear was devised, they used their bare hands to capture or collect fish, crabs, shellfish, and other useful organisms in the sea, rivers, ponds, or lakes.

This is clearly a situation in which the possibility of the English dictionary will have loan words from a Hiligaynon origin to widen its listing of word tokens for fishing and aquaculture. This is in relation to the current developments and practices of OED to include words of foreign origin, which includes Philippine languages (Salazar 2014).

Some towns in the Province of Capiz, particularly in Pontevedra, still observe the traditional way of buying and selling their products which they call pamaylo as revealed in the conversation shown below:

Mangingisda (Fisherman): Abyan, anong ara ta da? [Friend, what do we have there?]

Tindera (Vendor): Damo ah may ara manok, itlog, atay kag batikolon, hotdog, may karne man [Many! There are chicken, egg, liver and gizzard, hotdog, and even meat].

Mangingisda (Fisherman): Pwede ko ni pamaylo akon kalkag kag pasayan. Ginpakita ang dala sa bayuyot kag ginhatag sa tinder [Can I barter my 'kalkag' (dried small shrimps) and shrimps? (Show what he has inside the buri bag and give to the vendor)].

Tindera (Vendor): Wala problema ah. Dal-a diri. Pila ini ang bili tanan? Kay kilohan ko kon pila ang baylo sina [No, problem. Give it to me. How much is the price of all these? I will weigh for their corresponding price]. 
Mangingisda (Fisherman): Kaw nada bahala mana-mana [You do the estimate].

Tindera (Vendor): Ano ang ibaylo mo? [What do you want for an exchange?]

The word pamaylo came from the word baylo, meaning 'exchange or barter. Every market day people from Pontevedra, Capiz particularly from the coastal areas come with their goods like fish, crabs, dried fish, or seashells and exchange or barter (without money involved) them with goods like vegetables, fruits, chickens, or ducks by those coming from the upland. Pamaylo or barter then becomes part of the culture of the people of Pontevedra, Capiz for it has been integrated in their way of life which is observed until now during a market day by fisherfolk and vendors from the upland.

The fishing and aquaculture terms were defined first and used in sentences before they were translated into Filipino and English. Words which have no specific equivalents were translated based on Newmark's (1988) method of transference.

Below is an example of translated fishing and aquaculture Hiligaynon terms found in the glossary:

Hiligaynon: pakas - ginpihak nga isda nga ginbulad sa init sang adlaw asta magmala

Filipino: daing - hinating isda na ibinilad sa init ng araw hanggang matuyo

English: dried fillet fish - fillet fish which was dried under the heat of the sun

Eco-translation promotes a culturally and locally anchored equivalence and distinctiveness grounded on its ecological usage and the manifestation of local knowledge.

\section{C O N C L US I O N}

The linguistic ethnography, coupled with eco-translation, directed the theoretical and methodological directions of this study towards linguistic diversity. The result is a trilingual glossary for fishing and aquaculture farming which anchors local knowledge with languages for wider communication. This provides an impetus for a more inclusive and authentic process of bringing out local knowledge. Furthermore, this study offers an ecologically aligned perspective in developing a trilingual glossary in farming and aquaculture.

The adaptation of eco-translation in the translation process and the implementation of linguistic ethnography presents a place-based inclusion of LK in the study of lexicography. This has allowed the local knowledge, presented in the source language, Hiligaynon, to be the centerpiece of the lexicographical activities which then has provided information on the unique linguistic features and the creative use of the language. The source language has informed the historical LK through the ecological use of fishing and aquaculture word tokens.

Language becomes a representation of the experiences in the environment; this shows a resemblance to other cultures' representations. Filipino, English, and Hiligaynon complement in promoting the local knowledge and the ecological truths of the community. In this case, the languages used for broader communication, English and Filipino, can challenge to embrace the ecological truths of the Hiligaynon language for fishing and aquaculture to make it inclusive. In the same token, the Hiligaynon language offers the Filipino and English languages distinct lexicons that can further extend the cultural and ecological inclusions of these two languages.

\section{RE F E R E N C E S}

Babelyuk O, Galaidin A. 2018. The Dao of ecotranslation in Polish and Ukranian translation. Periodyk Naukowy AkademiiPolonijnej.28: DOI: http://dx.doi.org/10.23856/281.

Bassnett S. 2012. Translation Studies. Shanghai: Shanghai Foreign Language Education Press.

Carvalho AM, Frazão-Moreira A. 2011. Importance of local knowledge in plant resources management and conservation in two protected areas from Tras-os-Montes, Portugal. Journal of Ethnobiology and Ethnomedicine (7):36.

Du HB. 2012. An overview of eco-translatology study. Journal of Liaoning Educational Administration Institute (2): 78-81.

Emerson R, Fretz R, Shaw L. 1995. Writing Ethnographic Fieldnotes. Chicago: University of Chicago Press.

Ethnologue: Languages of the World. 2018. Summer Institute of Linguistics (SIL). https://www.ethnologue.com. 
Gee JP. 1999. An introduction to discourse analysis: Theory and method. NY: Routledge

Goffman E. 1989. On fieldwork. Journal of Contemporary Ethnography 18(2): 123-132. https://doi. org/10.1177/089124189018002001

$\mathrm{Hu}$ GS. 2011a. Eco-features of eco-translatology and the implications to translation studies. Foreign Languages Research in China (6): 69-109.

Hu GS. 2011b. Eco-translatology: Research foci and theoretical tenets. Chinese Translators Journal (2): 5-9.

Hu GS. 2008. Eco-translatology: A primer. Chinese Translators Journal (6): 11-15.

Hu GS. 2004. An Approach to Translation as Adaptation and Selection. Wuhan: Hubei Education Press.

Larson ML. 1984. Meaning-Based Translation: A Guide to Cross-Language Equivalence. University Press of America, Lanham, MD.

Munday J. 2012. Introducing Translation Studies: Theories and Applications. London: Routledge.

Newmark P. 1988. A Textbook of Translation. London: Prentice Hall.

Nietschmann B. 1989. Traditional sea territories, resources and rights in Torres Strait. In: JC Cornell. A Sea of Small Boats: Customary Law and Territoriality in the World of Inshore Fishing, Report No. 62, Cultural Survival, Cambridge, Mass., p 337-370.

Palomares MLD, Pauly D. 1992. FISHBASE as a world-wide computerized repository on Ethnoichthyology or indigenous knowledge on fishes. In: International Symposium or Indigenous Knowledge (TK) and Sustainable Development, September 20-26, 1992, International Institute of Rural Reconstruction (IIRR), Silang, Cavite, Philippines.
Rampton B, Maybin J, Tusting K. 2007. Linguistic Ethnography: Links, Problems and Possibilities. Journal of Sociolinguistics, 11(5).

Raymond CM, Fazey I, Reed MS, Stringer LC, Robinson GM, Evely AC. 2010. Integrating local and scientific knowledge for environmental management. Journal of Environmental Management (91): 1766-1777.

Ruddle K. 2000. Systems of Knowledge: Dialogue, relationships and process. Environment, Development, and Sustainability (2): 277-305.

Ruddle K. 1993. The transmission of traditional ecological knowledge. In: JT Ingles. Traditional Ecological Knowledge: Concepts and Cases, Canadian Museum of Nature and IDRC, Ottawa, $p$ 17-31.

Ruddle K, Akimichi T. 1989. Sea tenure in Japan and south-western Ryukyus. In: JC Cornell. A Sea of Small Boats: Customary Law and Territoriality in the World of Inshore Fishing, Report No. 62, Cultural Survival, Cambridge, Mass., p 337-370.

Salazar D. 2014. Towards improved coverage of Southeast Asian Englishes in the Oxford English Dictionary. In: Lexicography ASIALEX 2014 1: 95-108.

Velardi P, Poler R, Tomás JV. 2014. Methodology for the definition of a glossary in a collaborative research project and its application to a European Network of Excellence. In: ASIALEX 2015 Words, Dictionaries, and Corpora: Innovations in reference science. Hong Kong Polytechnic University, Hong Kong.

Zhang W. 2017. Study on the development of English translation of Chinese classics from the perspective of ecotranslatology. In: 3rd International Conference on Social Science and Technology Education (ICSSTE 2017), Institute of International Education, Xiangnan University, Chenzhou, Hunan, 423000 China. 